\title{
Experimentações literárias: práticas de leituras e experiências artísticas em escolas
}

\author{
Literary experimentations: reading practices and \\ artistic experiences in schools
}

\section{Experimentaciones literarias: prácticas de lecturas y experiencias} artísticas en escuelas

\author{
Roselusia Teresa de Morais Oliveira!
}

https://orcid.org/0000-0002-98/8-9977

\begin{abstract}
Resumo: $O$ presente estudo analisa atividades pedagógicas experimentais que priorizam práticas de leituras em instituições escolares, por meio de espaços de trocas de livros, leituras coletivas, experiências artísticas e compartilhamento de experiências leitoras com crianças e estudantes universitárias, em um projeto de pesquisa e extensão que tem como campo de atuação as escolas públicas. $O$ foco de análise são as práticas de leituras a partir de aspectos relacionados aos respectivos usos que considerem a forma e os objetos, os suportes e objetivos imbricados no ato de ler. Para isso, são considerados os "protocolos de leitura" (Chartier, 1996) e as "significations plurielles et mobiles" (Chartier, 2002a). A abordagem teórica e metodológica admite que as práticas de leituras produzem sentidos, mobilizam o corpo que interage com o livro, consigo e com o(s) outro(s), ou seja, posições corporais que, por sua vez, ocupam um lugar, e práticas circunscritas, em consonância com os hábitos culturais de um tempo.
\end{abstract}

Palavras-chave: Livros. Leitura. Experimentação literária.

Abstract: This study analyzes pedagogical activities that prioritize reading practices in schools, by doing book exchange, group reading, artistic experiences and shared reading with children and university students, in a research and extension project at the public schools. The focus of this analysis are the reading practices and the aspects related to their use, regarding the shapes, the objects, the tools and the aims of the reading process. For this reason, not only "reading protocols" (Chartier, 1996) and as "significations plurielles et mobiles" (Chartier, 2002a). The theoretical and methodological approach used admits that reading practices produce senses and make the body interact with the book, with itself and with other people, which means those practices produce body positions that occupy space and practices related to cultural components.

Keywords: Books. Reading. Literary experimentation.

\footnotetext{
${ }^{1}$ Doutora em Educação pela Universidade Federal de Pelotas (UFPel - RS), com Doutorado Sanduíche realizado na Université de Cergy-Pontoise, na França, por meio do Programa Institucional de Bolsas de Doutorado Sanduíche no Exterior (CAPES). Professora Adjunta do Departamento de Educação, da Universidade Federal de Sergipe (UFS). Líder do Grupo de Estudos e Pesquisas Relicário (Redes de leituras inscritas: cultura letrada, apropriações, representações e operações do ato de ler- DED/UFS/CNPq). E-mail: roselusiamorais@gmail.com
} 
Resumen: El presente estudio analisa actividades pedagógicas experimentales que priorizan prácticas de lecturas en instituciones escolares, por medio de espacios de intercambio de libros, lecturas coletivas, experiencias artísticas e intercambio de experiencias lectoras con niños y estudiantes universitarias, en un proyecto de investigación y extinción que tiene como campo de actuación las escuelas públicas. El centro de atención de análisis son las prácticas de lecturas a partir de aspectos relacionados a los respectivos usos que consideren la forma y los objetos, los soportes y objetivos imbricados en el acto de leer. Para eso, son considerados los "protocolos de lectura" (Chartier, 1996) y las "significations plurielles et mobiles." (Chartier, 2002a). El abordaje teórico y metodológico admite que las prácticas de lecturas producen sentidos, movilizan el cuerpo que interactúa con el libro, consigo y con el/los otro(s), o sea, posiciones corporales que, por su vez, ocupan un lugar, y prácticas circunscriptas, en consonancia con los hábitos culturales de un tiempo.

Palabras-clave: Libros. Lectura. Experimentación literária.

\section{Experimentações: palavras iniciais}

Eu sei que ler, ouvir, dizer poesia, hoje, nesse tempo de tanto desapego, de tanta correria, é uma tarefa difícil; é como provocar o mundo, ofender o mundo. Vivemos como se não coubesse mais o silêncio, as delicadezas, mas cabem! Isso me comove e me atrai (BETHÂNIA. 20I5, s/p).

Experimentar. Ler. Escutar. Sentir. Provocar. Aprender. (Re)inventar a si e o mundo. Estas palavras iniciais traduzem um convite para habitar um território, uma proposta pedagógica que compreende o entrelaçamento da vida cotidiana, a constituição de espaços e tempos para a leitura literária pela via da composição de experimentações artísticas. As produções artísticas, em suas múltiplas linguagens de descoberta e (re)interpretação do mundo, significaram possibilidades de criação, invenção e reinvenção dos processos de aprender. Em diálogo com as crianças e com as professoras da escola-campo, essas aprendizagens foram mediadas por experiências estéticas, potencializadas pela curiosidade, pelo interesse, pelas falas e perguntas das crianças.

Os princípios teórico-metodológicos deste trabalho estão ancorados nas experimentações e investigações realizadas pelo Grupo de Estudos e Pesquisa Relicário (Redes de leituras inscritas: cultura letrada, apropriações, representações e operações do ato de ler), vinculado ao Departamento de Educação (DED), da Universidade Federal de Sergipe (UFS), e cadastrado no Conselho Nacional de Desenvolvimento Científico e Tecnológico (CNPq) desde 2016. Especialmente, durante o período de 2016 a 2019, o Grupo Relicário desenvolveu experimentações de leitura literária que mobilizaram os sentidos de crianças matriculadas na Educação Infantil e no Ensino Fundamental em escolas públicas. Foram realizadas oficinas de leitura em parceria com as acadêmicas do curso de Pedagogia do Campus Professor Alberto Carvalho da UFS, e docentes das escolas campo, em diversos projetos de ensino, pesquisa e extensão que contemplaram escolas da rede municipal e estadual de ensino, situadas na cidade de cidade de Itabaiana, no estado de Sergipe. ${ }^{2}$ O presente estudo tem como propósito

\footnotetext{
${ }^{2}$ Neste trabalho, o foco da discussão está centrado nas atividades desenvolvidas em uma turma da educação infantil do Centro Educacional Vicente Machado Menezes e uma turma do ensino fundamental da Escola Estadual Eliezer Porto, situadas no município de Itabaiana-SE. Com o público-alvo de crianças de três anos de idade e um
} 
apresentar reflexões a partir das ações significativas desenvolvidas em projeto de pesquisa, extensão e de iniciação à docência, vinculado à UFS, com o recorte do período de execução que compreende os anos de 2018 e 2019.

Os princípios norteadores foram fundamentados na "abordagem triangular", ancoradas em Ana Mae Barbosa (2010), na experiência leitora e da "aprendizagem inventiva" de Virgínia Kastrup (200I, 20I5), na poética de Manoel de Barros (2008, 2009, 20I0), na inspiração da artista Lygia Clark (1920-1988), e almejaram experimentar as sensações, os sentidos das crianças, dos licenciandos, das professoras envolvidas nas vivências.

Os objetivos de ambos os projetos em questão foram: a) promover espaços de leitura em instituições escolares; b) mapear os interesses de leitura dos sujeitos envolvidos; c) verificar as "disposições" e "modos de ler" dos leitores; d) contribuir na avaliação e planejamento das atividades pedagógicas que promovam a formação de leitores. Os desdobramentos desses objetivos foram concretizados a partir de ações como: a constituição de acervo permanente de obras; planejamento e execução de oficinas literárias; articulação do tripé extensão-ensino-pesquisa; pesquisa bibliográfica sobre a temática do projeto; organização de oficinas de leitura literária em eventos acadêmicos e promoção de feira de livros.

O foco central em discussão deste artigo são as práticas de leituras a partir de aspectos relacionados aos respectivos usos que considerem a forma e os objetos, os suportes e objetivos imbricados no ato de ler. A abordagem teórica e metodológica admite que as práticas de leituras produzem sentidos, mobilizam o corpo que interage com o livro, consigo e com o(s) outro(s), ou seja, posições corporais que, por sua vez, ocupam um lugar, e práticas circunscritas, em consonância com os hábitos culturais de um tempo. Desse modo, revelam-se convenções, normas e valores, em seus contextos específicos. Para isso, são considerados os "protocolos de leitura" (Chartier, 1996), a interação leitor e texto, os limites e regras para as ações de leitura, e, portanto, as "significações plurais e móveis" (Chartier, 2002) capazes de inventar, deslocar ou subverter as ideias previamente pensadas pelo escritor do texto. Nesta direção, o eixo central em discussão são as "significações" atribuídas à leitura

total de vinte e duas crianças matriculadas na primeira turma e crianças de 8 anos de idade com vinte e uma crianças na segunda turma. No que se refere aos princípios e procedimentos éticos na realização da pesquisa, os responsáveis legais das crianças, as estudantes e professoras das escolas campo envolvidas nos projetos, tiveram conhecimento do conteúdo do projeto em execução, e assinaram o Termo de Consentimento Livre e Esclarecido - TCLE. A equipe diretiva das escolas e professoras tiveram acesso aos escritos do projeto na íntegra, por correio eletrônico e em sua versão impressa. E, no caso das crianças, tivemos acesso aos termos assinados pelos responsáveis legais, e ao longo das práticas de leituras, foram observadas as reações e expressões das criançasparticipantes, para cuidadosamente respeitar quaisquer sentimento de constrangimento ou declínio de participação de forma momentânea e/ou definitiva, respeitando assim os protocolos éticos, conforme orientações disponíveis em: http://www.anped.org.br/news/comissao-da-anped-apresenta-documento-etica-epesquisa-em-educacao-subsidios (ANPED, 2019).

Olhar de professor, Ponta Grossa, v. 24, p. I-2I, e-17689.082, 202I.

Disponível em <https://revistas2.uepg.br/index.php/olhardeprofessor> 
a partir das práticas inscritas em uma rede social e cultural, expressas a partir das especificidades e procedimentos nos modos e tipos de leituras.

\title{
Práticas de leitura: uma abordagem teórica e metodológica sobre os "modos de ler", as "operações" e a "produção de sentido"
}

\begin{abstract}
A leitura não é somente uma operação abstrata de intelecção: é por em jogo o corpo, é inscrição num espaço, relação consigo ou com o outro. Por isso devem ser reconstruídas as maneiras de ler próprias a cada comunidade de leitores, a cada uma dessas 'interpretative communities' 3 de que fala Stanley Fish (CHARTIER, 2002a, p. 70).
\end{abstract}

A leitura envolve diversos elementos que precedem a prática efetiva do ato de ler, processos que remetem à constituição da materialidade dos objetos da leitura, os materiais específicos, o "uso do corpo", a "inscrição em um espaço", a "relação consigo e com o outro", segundo Chartier (2002a, p. 70). Nesta direção, as práticas de leitura não são apenas operações "abstrata de intelecção", mas compreendem as "significações plurais" e "móveis" localizadas em uma espécie de consonância com os hábitos culturais de um determinado tempo, ou seja, os modos de ler referem-se às práticas inscritas em uma rede social e cultural específica, não sendo, portanto, atemporais. Considerar essa perspectiva, segundo Chartier (1990), significa pesquisar as modalidades de ler, sejam elas coletivas ou individuais, herdadas ou inovadoras, populares ou letradas, íntimas ou públicas, intensivas ou extensivas, orais ou silenciosas.

Este trabalho compreende conceitualmente os modos de ler e o processo pelo qual os leitores dão sentidos aos textos dos quais se apropriam. Essa perspectiva é discutida por Chartier (2002a) como a possibilidade de pensar a "produção da significação", o que implica uma relação dialógica entre as propostas das obras e as categorias estéticas e interpretativas de seus públicos leitores. Além de refletir a interação dinâmica entre o texto e o leitor, as práticas ordinárias e as experiências de vida dos leitores.

Os princípios teórico-metodológicos adotados destacam as investigações acerca da história do livro e da leitura, com ênfase nos estudos de Robert Darnton (1995, 2010); e Roger Chartier (1990, 1991, 1994, 1996, 2002a, 2002b, 2004, 2009). As análises de Michel de Certeau (1994) auxiliam na interpretação dos dados coletados no que se refere às relações entre as "operações" implicadas no ato de ler e os aspectos culturais intrínsecos na vida social que afetam diretamente as práticas de leitura dos leitores. Nesse campo teórico, os estudos acerca de práticas culturais tornaram-se centrais reconhecendo todas as experiências humanas como produções culturais. Assim, as experiências

\footnotetext{
${ }^{3}$ Tradução livre: comunidade interpretativa. 
cotidianas dos sujeitos, a exemplo das práticas de leitura, são expressões de práticas culturais que incluem ações, sentidos, representações, rituais.

Chartier (1990) afirma que, entre os teóricos, Norbert Elias discute as formações sociais e culturais de modo descontínuo e considera, portanto, categorias filosóficas, psíquicas e formas de experiência da leitura, por exemplo. Em sentido contrário, o autor francês afirma que Paul Ricoeur é um exemplo de teórico que buscou uma teoria baseada na fenomenologia do ato de ler e na estética da recepção. A finalidade deste último era refletir sobre como o texto é efetivado, quais são os significados atribuídos a partir dos "significantes", como as palavras, as frases, os sinais e símbolos dados a partir da leitura, ou seja, o sentido denotativo. E, além disso, o outro fim era compreender como o texto é apropriado pela experiência de leitura como condição necessária para que o indivíduo se constitua e compreenda a si mesmo e o mundo ao seu redor. Desse modo, as configurações registradas nos textos constroem representações que são "aceitas" ou "impostas do mundo social" a partir das "modalidades da sua recepção". Chartier (1990) julga criticamente essas vertentes mencionadas, a fenomenologia e a estética da recepção, por não admitir de fato a individualidade e situar o tempo histórico.

Segundo Michel de Certeau (2008), a leitura faz parte das práticas cotidianas daqueles que consomem produtos e realizam diversas ações tais como comprar, cozinhar, habitar, circular, falar. Para $\circ$ autor, todas essas atividades parecem corresponder às características das astúcias e das surpresas táticas. Baseado em Certeau (2008), entende-se que as estratégias supõem lugares e instituições, produzem objetos, normas e modelos, acumulam e capitalizam. As táticas, desprovidas de lugar próprio, sem controle sobre o tempo, são "maneiras de fazer" (CERTEAU, 2008, p. 120).

A materialidade do texto dispõe de formas que "dão a ler, a ouvir ou a ver" (CHARTIER, 2002a, p. 256), e que compõem a construção de sua significação, como "dispositivos de sua inscrição ou de sua comunicação" (CHARTIER, 2002a, p. 256), ou seja, há uma relação intrínseca da forma de ler com a produção de sentido. Além dos "dispositivos de inscrição", há os "dispositivos formais" como a representação teatral, recitação, leitura em voz alta, entre outros, que determinam as diversas relações sociais que o público mantém com a obra. Outro aspecto, considerado por Chartier (2002a, p. 256), é a "corporalidade do leitor" que depende das capacidades, dos códigos e das convenções de leitura próprios às diferentes comunidades que constituem, na sincronia ou na diacronia, seus diferentes públicos. Portanto, o estudo das "significações" deve considerar essas diferenças que estão atreladas na especificidade do ato de ler.

Para analisar as práticas de leitura - seja do passado ou do presente - há diferentes perspectivas metodológicas e teóricas possíveis, por exemplo, a proposta de um modelo geral para analisar como os livros são produzidos e se difundem na sociedade, conforme o referencial de Darnton (1995, p. 
II2) que aponta um "circuito de comunicação". Essa conceituação compreende as seguintes esferas: produção, edição, distribuição, circulação do livro e, por fim, o leitor. Esse "circuito" admite que há variações das condições conforme o lugar e a época, mas de modo geral pode ser descrito em um modelo que considera o percurso desde o autor, o editor, o impressor, o distribuidor, o vendedor até chegar às mãos do leitor. Neste trabalho, é analisado um aspecto desse "circuito" que é a instância do leitor, considerado uma das mais difíceis de acessar nos estudos porque nem sempre os leitores "de carne e osso" deixam registros de suas práticas de leitura (DARNTON, 1995).

A produção de sentido em leitura significa explicitar como os leitores compreendem a si próprio e o mundo, por meio da relação estabelecida com o "mundo do texto". Portanto, a leitura é entendida como um "ato concreto" que requer leitores dotados de "competências específicas" e caracterizados pela sua prática de ler que constrói sentido, ou seja, uma interpretação. A pesquisa também problematiza práticas específicas que definem: processos de construção de sentido, interpretações decorrentes da leitura, condições de leitura e os seus processos, ou seja, as "operações de produção de sentido" e as apropriações.

O contexto do leitor e autor é abordado por Umberto Eco (2003), em "Obra aberta", ao apontar a existência de uma "cooperação interpretativa" por parte dos leitores ao lerem os textos. Isso porque no processo de leitura, para que se possa compreender a obra, o leitor a reinventa "num ato de congenialidade com o autor", nas palavras de Eco (2003, p. 4I). Em resumo, no ato interpretativo entra em jogo a intenção do autor e do leitor que traz consigo, ou seja, a contribuição do leitor ao interpretar uma obra.

Em virtude disso, os leitores desenvolvem mecanismos para construção do sentido sobre o que leem e expectativas suscitadas a partir do texto no seu contexto particular. No livro "Lector in fabula", o texto é definido como "[...] uma máquina preguiçosa, que exige do leitor um renhido trabalho cooperativo para preencher espaços de não-dito ou de já-dito que ficaram, por assim dizer, em branco [...]” (ECO, 2004, p. II). Dessa forma, compreende-se que o leitor, ou “destinatário”, atualiza o texto como "condição indispensável não só da própria capacidade concreta de comunicação, mas também da própria potencialidade significativa" (ECO, 2004, p. 37). Portanto, a obra pode ser interpretada de diferentes formas, uma vez que o leitor, ou "intérprete" imagina as circunstâncias sugeridas a partir da leitura e, assim, estimula a liberdade interpretativa ao reconfigurar para si as mensagens do autor de acordo com suas próprias vivências e sua cultura.

É possível considerar a complexidade e as dificuldades em definir e identificar como os leitores assimilam as suas leituras e quais são os efeitos produzidos pelos textos lidos, conforme os estudos de Robert Darnton (1995). Para os pesquisadores como Darnton (1995) e Chartier (2002a), essa dimensão da leitura - da produção de sentidos - é reconhecidamente complexa e de difícil acesso nas 
práticas dos leitores. Os aspectos relacionados às convenções, normas e aos valores atribuídos às leituras de obras são elementos reveladores dos modos de ler, da interação entre o leitor e o texto.

A leitura nem sempre foi praticada do mesmo modo, já afirmaram Cavallo e Chartier (1997), ela depende também do suporte, se é rolo, livro ou tela, assim como também do seu conteúdo. A leitura pode ser realizada rápida ou lentamente, silenciosa ou em voz alta. Pode ser ainda uma leitura privada ou pública. Tais características apontam que ao longo da história, os modos de ler nem sempre foram os mesmos, alteraram-se no decorrer dos anos e conforme a existência dos suportes diferentes, dos sentidos do ler, das representações da leitura. As formas materiais do texto impresso interferem e possibilitam "efeitos de sentido" (CHARTIER, 2002a, p. 27I). Os livros e sua materialidade indicam também uma representação do que é e como deve ser a leitura literária: no livro e com o livro.

Em várias obras, Roger Chartier analisa práticas de leitura de diferentes grupos e contextos históricos ao considerar os "modos de ler". O pesquisador estuda desde práticas de leitura do Antigo Regime até as práticas atuais relacionadas aos meios digitais. Os modos de ler, para Chartier (1994), apresentam mudanças significativas ao longo dos últimos séculos, especialmente. As práticas de leitura, segundo ele, estiveram condicionadas, seja na forma como o corpo se posiciona diante da leitura (leitura no rolo, leitura nos livros de grande dimensão, leitura na tela, e entre outros.); seja na intensidade ou extensividade da leitura, feita a partir de um restrito número de obras ou em uma quantidade expressiva de livros disponíveis (CHARTIER, 1994). Essas mudanças são observadas por Chartier (2000) como "revoluções da leitura", e a primeira delas aconteceu antes da invenção da imprensa, no período anterior ao século $\mathrm{XV}$, com a passagem da leitura oral para a silenciosa ou visual. Isso significou uma nova relação de maior liberdade entre o leitor e o texto, uma vez que a leitura silenciosa proporcionou um vínculo mais dinâmico e íntimo com o impresso, o que permitiu a ampliação de um número maior de obras. Outra revolução das práticas de leitura foi a passagem da "leitura intensiva", na qual o texto era comumente lido e relido, memorizado e recitado, para a "leitura extensiva", ou seja, uma prática silenciosa e individual que também podia significar a leitura de diferentes obras ao mesmo tempo. Embora a prática intensiva venha sendo substituída pela leitura extensiva, as duas práticas coexistiram ao longo do tempo.

Nessa direção, para Cavallo e Chartier (1997), a leitura não é meramente uma atividade intelectual, mas, além disso, a leitura supõe o uso do corpo, a utilização de um espaço e se ela acontece individualmente ou coletivamente. Isso porque "o modo de ler, que é ditado pelo livro ou por seus intérpretes, oferece o arquétipo de todas as formas de leitura, não importa quais sejam" (CHARTIER, 1992, p. 227). Considerou-se o princípio de que o ato de ler produz sentidos plurais e móveis que estão relacionadas às "maneiras de ler, coletivas ou individuais, herdadas ou inovadoras, íntimas ou

Olhar de professor, Ponta Grossa, v. 24, p. I-2I, e-17689.082, 2021.

Disponível em <https://revistas2.uepg.br/index.php/olhardeprofessor> 
públicas e de protocolos de leitura depositados no objeto lido [...] em conformidade com os hábitos de seu tempo" (CHARTIER, 200I, p. 78).

A relação que o leitor estabelece com o livro remete ao entendimento de Chartier (2002b), quando afirma que o processo de ler envolve diversos elementos que antecedem a prática efetiva do ato de ler. A constituição de materiais específicos para a leitura provoca e desperta os sentidos na leitora. A materialidade dos objetos de leitura desde o aspecto físico, imagens, disposição do texto, impressão e formato constituem elementos que compõem os momentos de leitura. Essa discussão revela que no processo de interação com um texto, o leitor atribui significados, a partir de sua história e de suas experiências, ou seja, é distinto para cada leitor, uma vez que, as experiências, a origem e a história dos leitores nunca são iguais.

Aliada a essa perspectiva, e fundamentado em Vincent Jouve (2008), a noção de leitura e de competência para ler é compreendida como uma atividade multifacetada que envolve processos neurofisiológicos, cognitivos, afetivos, argumentativos e simbólicos. Considerando esses aspectos, a leitura supõe determinadas competências que incluem as esferas individual e cultural. Isso acontece quando o leitor converte palavras em "elementos de significação" (JOUVE, 2008), o que promove ações de abstração. Assim, ele dedica a sua atenção para a sequência de eventos descritos no livro que lê ou não o acompanha de maneira linear, o que depende da relação do leitor com o enredo do gênero literário específico. Por isso, a depender do tipo de texto são produzidos determinados tipos de leitura que podem provocar o riso, o fascínio, a indignação, a tristeza, e entre outros sentimentos, de tal modo que suscitam os sentidos de múltiplas formas. Além disso, os sentidos atribuídos às leituras devem considerar os modos de ler inseridos em seus espaços e tempos específicos.

Esses fundamentos teórico-metodológicos auxiliaram a compreender perspectivas sobre o ato de ler e estruturar o planejamento de experimentações de práticas pedagógicas que compreenderam a leitura em seus usos e processos de produção de sentido. A elaboração e execução deste trabalho envolveram um planejamento coletivo, que buscou uma articulação entre as acadêmicas do curso de Pedagogia da UFS e os profissionais da escola-campo para a estruturação das práticas de leituras voltadas para crianças de três anos de idade, de uma turma de Educação Infantil da rede municipal de ensino, e para crianças de oito anos de idade de uma turma do Ensino Fundamental da rede estadual de ensino, de Itabaiana - SE. Portanto, as práticas de leitura, nas instituições escolares, potencializaram espaços de promoção e acesso aos livros e às leituras.

Olhar de professor, Ponta Grossa, v. 24, p. I-2I, e-17689.082, 202I.

Disponível em <https://revistas2.uepg.br/index.php/olhardeprofessor> 


\section{Experimentações de leituras nas escolas: tempo de reflexões sobre os usos e os modos} de ler

Ler demanda tempo.

(KASTRUP, 20I5, p. 245).

A prática de leitura inserida na cultura escolar se traduz por uma riqueza de detalhes e oferece a possibilidade de constituir significados e sentidos para o leitor. $O$ ato de ler significa não apenas compreender os diversos códigos e elementos que constituem o objeto de leitura, mas situam os códigos sociais, as relações estabelecidas nos seus lugares de convívio. (MORAIS, 20I4).

A esfera política e social do trabalho pedagógico conduz os sujeitos-leitores a luta pela superação das contradições da vida social, aquilo que Ezequiel Silva (1991) chama de "espírito crítico". É através da reflexão, do posicionamento e da ação transformadora que o indivíduo irá compreender a razão do mundo que o cerca, os fatos sociais. Para que isso aconteça é necessário verificar os conteúdos e as metodologias de leitura, ou seja, uma nova proposta para o ensino da leitura coerente entre os "[...] fins e meios, entre teoria e prática, entre discurso e ação [...]" (SILVA, I99I, p. 48). Apesar do autor adotar uma perspectiva que compreende a leitura como uma espécie de "salvação" para os problemas educacionais e sociais, cabe considerar que suas pesquisas no campo da leitura evidenciam o modo de conceber as práticas no âmbito da cultura escolar.

A literatura pode ser analisada como possibilidades educativas a partir das leituras recomendadas na esfera escolar, mas segundo Mathieu Bégin (201 I), raro é localizar pesquisas que se dediquem à literatura, como uma prática de divertimento, de socialização e de enriquecimento pessoal. Este trabalho identifica justamente tais dimensões raras em termos de pesquisa e apresenta reflexões sobre os usos da leitura no contexto educacional. Ainda para Bégin (20l I), é surpreendente analisar pelo viés da história das práticas de leitura como esse território foi e é explorado pelos leitores.

Silva (199I) propõe que a partir dessa diversidade de significados, os leitores junto ao professor partilhem e expressem os significados a que chegaram durante e após a interação com os textos. Essa abordagem permeia a construção desta proposta, uma vez que a problemática anunciada exige a produção e divulgação de iniciativas que busquem caracterizar e interpretar, cada vez mais, as práticas de leituras, incluindo, assim, possíveis causas e soluções para os seus respectivos problemas na formação de leitores.

A questão da leitura no Brasil, no início do século $X X I$, segundo os estudos da professora e pesquisadora Magda Soares (2008), tem ultrapassado as paredes da escola e discussões entre educadores, e ganhado espaço nos debates entre pais, políticos e outros profissionais de diversas áreas. A autora define o ato de ler como "prática social de interação", um "processo complexo e multifacetado", pois depende da natureza, tipo, gênero do que se lê e depende do objetivo que se tem 
ao ler. Para a pesquisadora, a faceta fundamental do problema consiste nas seguintes perguntas: "Quando se diz que o brasileiro lê pouco ou lê mal, o que se está entendendo por ler? Lê pouco o quê? Lê mal o quê?" (SOARES, 2008, p. 30). Essas questões também são problematizadas por Ezequiel Theodoro da Silva (|99|), ainda no fim do século XX, a partir de reflexões sobre o desenvolvimento a leitura no Brasil e os parâmetros que norteiam uma nova pedagogia da leitura. $O$ autor elabora vários questionamentos acerca da leitura no contexto escolar e no processo de alfabetização, evidenciando que as práticas de leitura exigem ações docentes comprometidas em assumir uma educação de um tipo específico de leitor, capaz de enfrentar as contradições e os desafios da sociedade. Em outras palavras, o autor aponta que a finalidade primordial dos trabalhos com leitura escolar é a formação de leitores questionadores, capazes de se situar conscientemente no contexto social e, ao mesmo tempo, compreender os processos de leitura.

Vera Masagão Ribeiro (2003) e Márcia Abreu (2006) também apresentaram reflexões sobre o desenvolvimento da leitura no Brasil, o debate em torno do letramento e os parâmetros sobre como definir literatura, se há bons livros em si, se todos devem apreciar o mesmo gênero textual. As autoras elaboram várias questões acerca da leitura no contexto escolar e promovem iniciativas para o debate sobre o estudo da leitura no país. Nessa perspectiva, a prática de leitura inserida em uma cultura traduz-se por uma riqueza de detalhes e oferece a possibilidade de constituir significados e sentidos para o leitor. $O$ ato de ler denota não apenas compreender os diversos códigos e elementos que constituem o objeto de leitura, mas situa os códigos sociais, as relações estabelecidas nos seus espaços de socialização.

No Brasil, segundo Lopes e Galvão (200I), a virada do século XX para o XXI demarcou a crescente elaboração de estudos centrados em temáticas relacionadas à produção, circulação e aos usos dos materiais impressos. Desse modo, os leitores tornaram-se objeto de investigação a partir dos modos de ler e da apropriação que fazem das leituras que realizam.

Considerando ainda os estudos de Maria da Graça Paulino (2008), este artigo compreende a leitura na perspectiva de localizar os objetos e procedimentos utilizados nos modos de ler, além de identificar as relações estabelecidas pelos sujeitos em seus espaços sociais e ações de leitura. Assim, cabe considerar esses aspectos como fundamentais para a problematização da relação leitor e texto, leitura e produção de sentido. É preciso considerar que as habilidades exigidas na leitura são "habilidades cognitivas, além de serem habilidades de comunicação, no sentido de habilidades interacionais e também afetivas", segundo Paulino (2008, p. 59). Os diversos discursos se definiram historicamente, em nível de produção e recepção, pela motivação e objetivos predominantes, pela interação verbal estabelecida. Esses "domínios discursivos" exigiriam e desenvolveriam habilidades complexas e competências sociais de seus leitores. 
Nessa direção, as ações realizadas no âmbito dos projetos em foco concretizaram a constituição de um acervo permanente de obras disponíveis para as acadêmicas integrantes do Grupo Relicário (CNPQ/UFS), acondicionado em uma das salas de reuniões dos professores, do Departamento de Educação, do Campus Professor Alberto Carvalho da UFS, para fins de acesso e planejamento das atividades desenvolvidas nas instituições escolares da rede pública de ensino. As escolhas dos livros foram feitas previamente em encontros de planejamentos e articulavam-se à escolha de leituras marcantes das acadêmicas do curso de Pedagogia e participantes dos projetos

A escolha dos livros literários foi definida pelas acadêmicas ao considerarem leituras marcantes em suas trajetórias como leitoras. $O$ projeto de extensão se articulou ao projeto de iniciação científica (PIBIC) intitulado: "Leitores, leituras e livros: memórias de estudantes universitários", foi aprovado pelo Edital $n^{\circ}$ 01/20I8/POSGRAP/COPES/UFS - PIBIC 2018/2019 (Período de realização: 01/08/2018 a 31/07/2019). As acadêmicas participantes elaboraram reflexões de cunho didático-pedagógico que priorizaram práticas de leitura no contexto escolar, seja na leitura de livros para crianças, e na promoção de feiras de troca-troca de livros, nos ciclos de estudos sobre literatura e oficinas artísticas.

$O$ ato de planejar e executar as práticas de leituras com as crianças estimularam o reconhecimento de si mesmas, dos seus espaços de convívio em suas particularidades, vislumbrando a construção de formas de pensar, provocando a criticidade e o intelecto, formulando conceitos coletivamente a partir da leitura de textos literários e o espaço de diálogo e interação de maneira espontânea. Os planejamentos de cada encontro com as crianças foram formulados a partir de encontros quinzenais com a equipe do projeto e em síntese, consistiam em três momentos previstos para a execução da atividade.

As temáticas dos livros escolhidos foram diversas ${ }^{4}$ e, por sua vez suscitaram a construção da identidade e da subjetividade, compreendendo como direitos de aprendizagem que correspondem à Educação Infantil e ao Ensino Fundamental, em especial, previstas desde as Diretrizes Curriculares Nacionais para a Educação Infantil (DCNEI), de 2010, até a Base Nacional Comum Curricular (BNCC), de 2018. Esses referenciais fundamentaram as principais ações desta proposta que, por sua vez, admitem a leitura literária e o contato com o livro como possibilidades de experimentação, intimamente interligadas aos sentidos e assim, pressupõem aprendizagens e desaprendizagens do

\footnotetext{
${ }^{4}$ Para conhecimento segue uma lista de alguns dos livros escolhidos: diversos poemas de Manoel de Barros (2008, 2009, 20 I0); "O que cabe no meu mundo: Amizade”, de Katia Trindade (s.d.); “É meu! Não empresto!" - Aprendendo sobre Generosidade de Claire Llewelly e Mike Gordon (2002); "O Menino Azul", de Cecília Meirelles (2013); "Cadê" de Guto Lins (2008); "Meus Queridos Contos Clássicos - Pinóquio" de Carlo Collodi (s.d.); "Uma zebra fora do padrão" de Paula Browne (20II); "Bruxinha Zuzu" de Eva Furnari (2010) e entre outros. Os livros selecionados em parte compõem o acervo da brinquedoteca do curso de Pedagogia, do Campus Professor Alberto Carvalho, da UFS, e o acervo particular das acadêmicas envolvidas nos projetos.
} 
conhecimento, construção e desconstrução de saberes, destacando a arte como uma via de intercâmbios de imagens e escritos.

A metodologia adotada buscou espaços para escuta atenta da fala das crianças no que se refere à formulação de perguntas após as leituras literárias permeadas por fantasia, indagações e criação. $O$ objetivo central foi provocá-las a pensar sobre o mundo que as cercam, a observar, elaborar ideias e criar suas próprias narrativas. Os encontros aconteceram uma vez por semana, previamente agendados com a coordenação da escola e consistiam em ler livros literários para as crianças e logo após, eram discutidos os principais temas da história. Em média, os encontros eram realizados em grupos de quinze a vinte crianças na sala de aula e duravam, aproximadamente, uma hora. A estruturação básica das práticas de leitura literária foi pensada a partir de três momentos e descritos, neste trabalho, em três episódios, conforme imagens a seguir:

Episódio I- Criando narrativas, experimentando e construindo um mosaico: ressonâncias

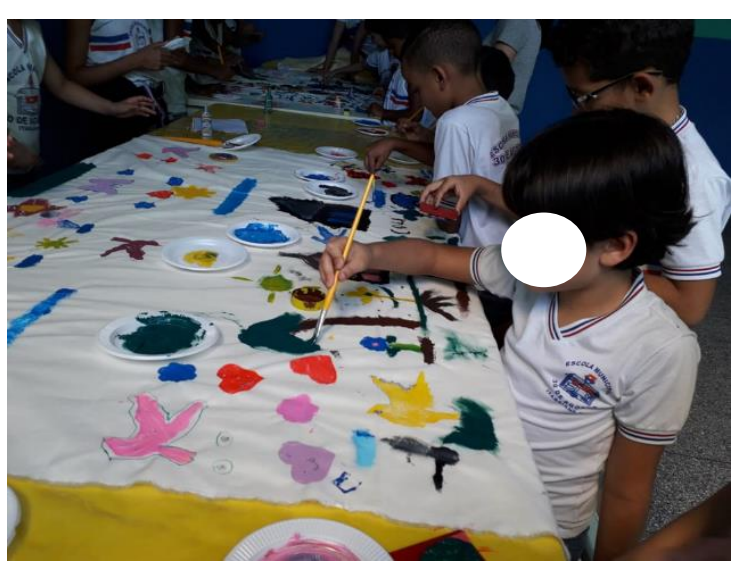

Figura I

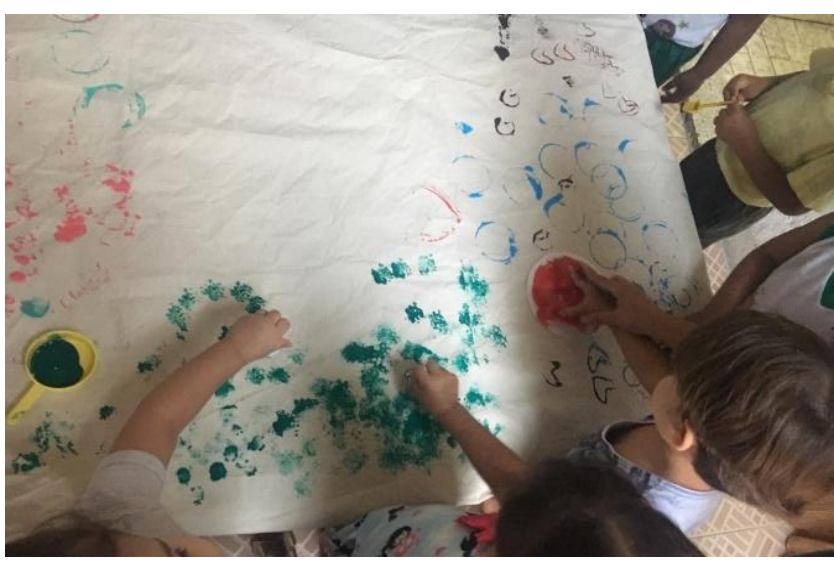

Figura 2

Fonte: Acervo da pesquisadora, 2019.

No episódio I, inicialmente, foi dedicado um momento de preparação que consistia em propor uma interação com as crianças por meio de uma canção, antes da leitura dos livros. Essa proposta foi pensada em mobilizar o corpo para a escuta atenta e sensível. As imagens revelam que o próprio ato de experimentar uma vivência mobiliza o seu campo de percepções, as crianças criam e contam as suas próprias histórias, ou em alguns momentos, em silêncio, atentas aos materiais disponíveis, exploram o mundo a partir dos seus sentidos. O episódio I evidencia duas turmas distintas, com usos dos materiais de maneira exploratória, inventiva e poética. $\mathrm{Na}$ imagem I, a esquerda, no canto inferior direito, uma mão amiga estende e se oferece para fazer junto, uma das crianças auxilia na condução da pintura em tecido unindo as suas mãos em uma construção poética, coletiva e inventiva. Já na imagem 2, a direita, em uma outra turma, as crianças usam estratégias para colocar suas formas, demarcando os seus próprios espaços de pintura e contornando os seus territórios de escrita. A experiência com a 
literatura e com a arte em geral caracteriza-se "por um tempo de ressonâncias", conforme Kastrup (2015, p. 246).

Assim, como também é possível observar no Episódio 2, outras vivências artísticas em diálogo com elementos disponíveis na natureza e esse "tempo de ressonâncias":

\section{Episódio 2 - Compondo com elementos da natureza}

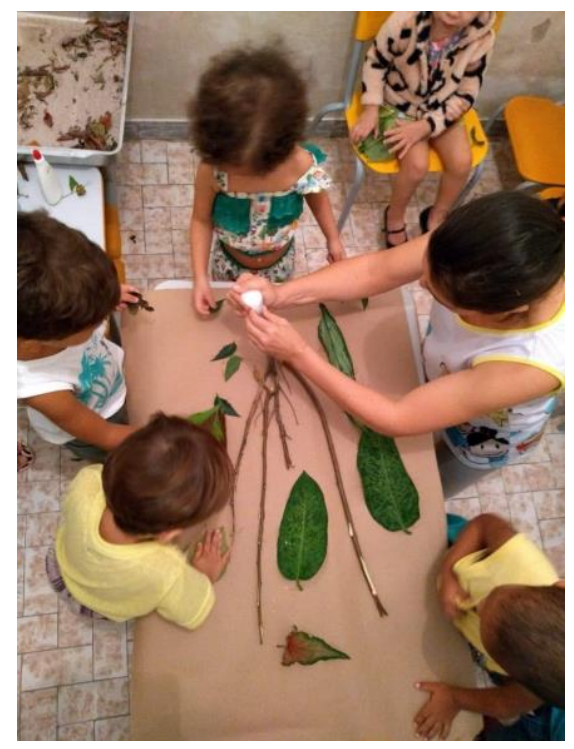

Figura 3

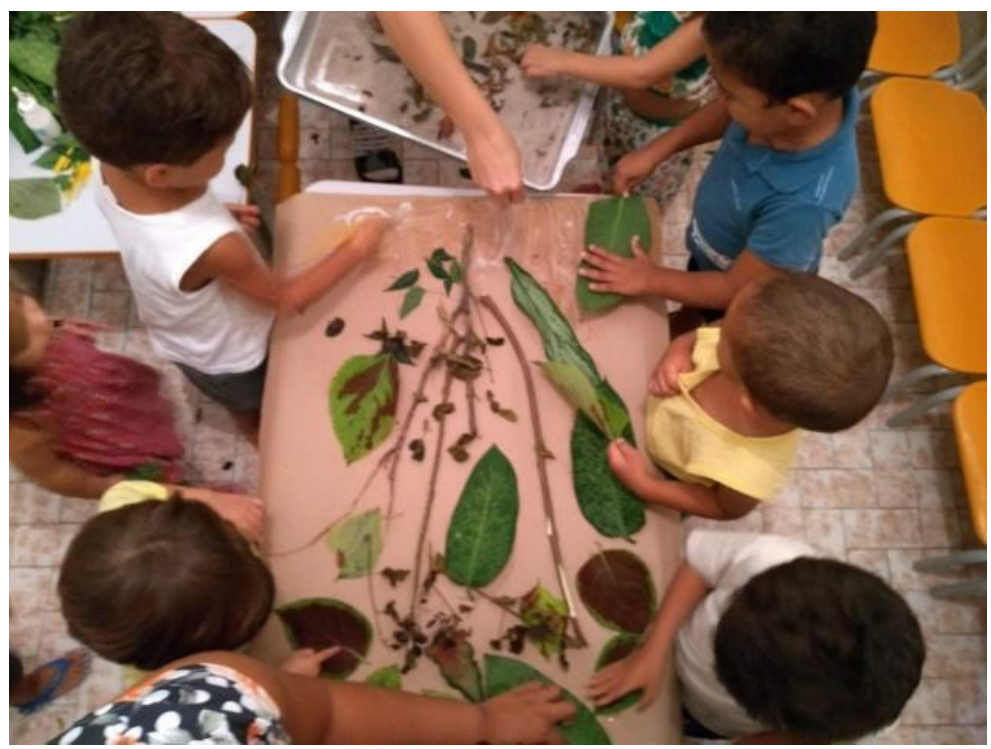

Figura 4

Fonte: Acervo da pesquisadora, 2019

No episódio 2, os diálogos com as crianças foram mediados por uma produção artística a partir de compartilhamentos de impressões das leituras e feitura de um registro artístico imagético. Nesse sentido, foi proporcionada uma experimentação artística potente que dialoga com artefatos manuais ao manipular com elementos da natureza (como galhos, pedrinhas, folhas secas, areia, argila), tintas diversas, com diferentes texturas e cores, como pode ser visualizada nas figuras 3 e 4 .

Elementos recolhidos no chão do pátio e arredores da escola, junto com as crianças, as formas da natureza dão novos contornos sob o papel. Coletivamente, cada uma decidiu e disse onde colocar as formas distintas que progressivamente ganham traços compartilhados. A participação aconteceu de vários modos: a) algumas crianças que ficaram sentadas ou em pé, próximo da vivência, e se colocaram na posição de observadoras; b) outras crianças auxiliaram na colagem, questionando, explorando e escolhendo os itens para compor; c) já outras crianças, silenciosamente, manipularam os objetos. As distintas manifestações das crianças revelam como cada uma delas sentem e expressam essa singularidade que pode ser preservada e permitida nos contextos educacionais a partir de vivências que acolham os seus movimentos, os seus ritmos, as suas preferências e a sua interação. 
Os principais fundamentos teórico-metodológicos que embasam as práticas pedagógicas concebem o brincar na infância a partir de elementos da natureza e a interação da criança com esses recursos. Desse modo, auxiliam repensar a sala de aula e aquele que aprende, e desse modo, reinventar e reelaborar os espaços e o modo de relacionar-se com os outros e consigo. Em síntese, refere-se às propostas de experiências sensoriais que mobilizam os sentidos e assim, concebem novos modos de experimentar a sala de aula. O intercâmbio proposto a partir da Literatura e experimentações artísticas também propõe um importante recurso imagético a partir da construção de um caderno de artista revelador das memórias de leitura, conforme o Episódio 3 a seguir:

Episódio 3- Construindo cadernos de artista: memórias de leituras literárias

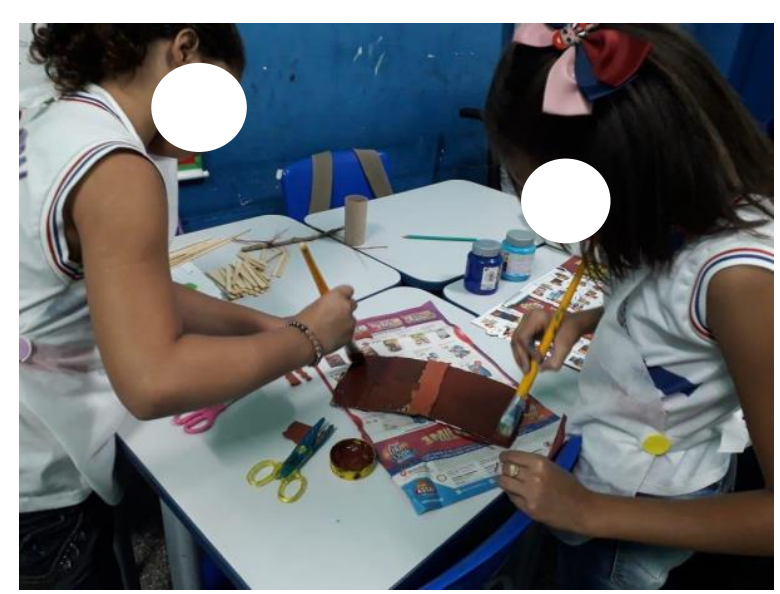

Figura 5

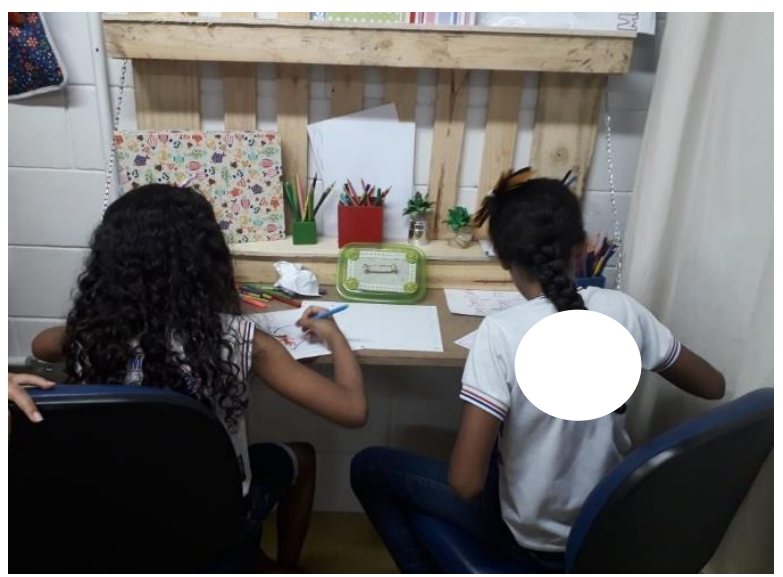

Figura 6

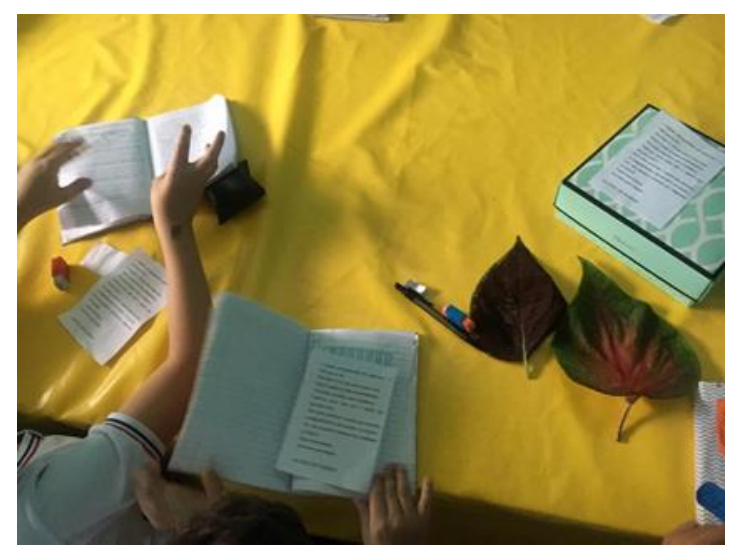

Figura 7

Fonte: Acervo da pesquisadora, 2019.

Nessa etapa a vivência crucial foi fundamentada a partir dos fundamentos teóricos e metodológicos elencados anteriormente, ancorados no princípio de interação entre leitor/ leitoralivro- ledora, manipulação dos suportes impressos, escuta da história narrada pela ledora; interrogação 
das narrativas por meio das interpelações espontâneas das crianças. As imagens evidenciam as mãos envolvidas no próprio ato de criação e compõem novas narrativas e memórias a partir das práticas de leituras literárias experimentadas. A construção do caderno de artista admitiu recortes, colagens diversas, usos dos mais diferentes recursos disponíveis, cores variadas, transcrição de trechos significativos de leituras literárias, pintura, construção da capa do caderno e entre outras possibilidades inventivas. $O$ objetivo central foi construir um espaço de memórias das leituras literárias, dos momentos vividos, um tempo de criação a partir das ressonâncias do tempo de ler. Inspirado em Suzuki (2014) o caderno de artista no espaço escolar é autobiográfico, trata-se de um documento histórico-cultural, é um espaço para livre associações e portanto, um meio fértil para que o instante criador se materialize. Nesta direção, é um espaço que potencializa a autoria, acolhe a reflexão constante e permite a invenção, uma vez que o caderno de artista trata-se de: "[...] uma ferramenta presente no aprendizado artístico, adentrou o universo da escola impulsionado por um movimento constante de problematização do cotidiano escolar e de uma atenta observação das relações de aprendizagem tecidas nesse contexto.", de acordo com Suzuki (2014, p. I).

Revelam as ressonâncias do ato de ler, manipulam texturas diversas, ampliam o olhar sobre a natureza, dialogam com os olhares buscando as minúcias. Indicam ainda que as experiências podem promover processos de aprendizagem, "incitando sempre à recriação, o que faz com que a experiência do leitor continue o processo de criação do escritor", conforme Kastrup (2015, p. 247). Nesta vertente, a aprendizagem da Literatura e Artes oferece no cenário educacional a possibilidade de um convite, de uma mudança de perspectiva ou aprendizagem problematizada, assim:

[...] Esta questão é importante, pois quando falamos em aprendizagem inventiva não entendemos a invenção como algo raro e excepcional, privilégio exclusivo de artistas ou mesmo de cientistas. $O$ interesse é pensar a inventividade que perpassa o nosso cotidiano e que permeia o funcionamento cognitivo de todos nós [...] (KASTRUP, 200I, p. 19).

Os episódios apresentados foram marcados pelo envolvimento das crianças com as professoras-leitoras, de modo progressivo, elas ampliavam as suas indagações, criavam outras narrativas e faziam a relação texto-imagens apresentadas no movimento de folhear os livros. Durante a leitura atenta de uma das acadêmicas que compõe o projeto, as crianças se aproximavam mais do livro, horas para ver mais de perto, horas para apontar nas imagens os objetos que reconheciam e até mesmo produziam sons e gestos com o corpo, de maneira espontânea. Desse modo:

[...] acreditamos que as atividades multissensoriais podem levar $\circ$ aluno a experimentar o mundo do texto por meio de estímulos sensoriais e afetivos, antes mesmo de ele experenciá-lo por meio das palavras; podem despertar a atenção do aluno, ajudando-o a se concentrar no momento da leitura e a reter o conteúdo estudado; podem contribuir para aumentar os graus de compreensão do texto a

Olhar de professor, Ponta Grossa, v. 24, p. I-2I, e-17689.082, 2021.

Disponível em <https://revistas2.uepg.br/index.php/olhardeprofessor> 
interpretar e podem ajudar, também, a estabelecer, nas aulas de leitura, um relacionamento inédito do corpo com o texto escrito (ANDRADE; FERES, 2018, p. 429).

Partindo dessa perspectiva, o entendimento de toda a equipe do projeto na condução das atividades de leituras foi contrapor a experiência de que não é suficientemente importante pegar "qualquer" livro da biblioteca, e tão somente utilizar as entonações, ritmos e efeitos de som na fala para que as crianças fiquem deslumbradas ou estimulem a fantasia, mas provocar novas formulações, novas histórias, contornando o próprio universo das crianças assistidas, permitindo assim, a expressão de suas emoções. Ao final de cada leitura, as crianças perguntavam se poderiam ler a história novamente e questionavam o retorno à escola no dia seguinte. A finalização de cada encontro era acompanhada de abraços que fortaleciam os vínculos entre as crianças, estudantes e professoras.

Este trabalho enfatiza o diálogo com outros pesquisadores da área que sinalizam reflexões pertinentes acerca da formação do leitor a partir de práticas pedagógicas em instâncias escolares, ações em espaços de leituras e a constituição de seus acervos de literatura potencializam o debate acerca da sua organização e do seu funcionamento. A discussão envolve, portanto, a importância do mediador como "incentivador" da leitura literária nas propostas educacionais, a integração dos trabalhos escolares compartilhados entre o grupo de educadores, nos programas de leituras propostos, assim como também indicado nos estudos organizados por Souza (2009).

Um dos princípios norteadores das práticas executadas do projeto desenvolvido consistiu em incentivar experiências que valorizassem a escuta do professor-leitor, a fala atenta, o pensamento e a imaginação das crianças. Partindo dessa premissa, admite-se que a construção de uma criança leitora não se resume apenas às técnicas e aos procedimentos de leitura, mas, na intrínseca necessidade envolvê-la nas diferentes narrativas literárias e assim, assumam processos de conhecimento de si e do outro mediados pelas experimentações artísticas apresentadas.

A interpretação dos encontros realizados pode ser entendida a partir da premissa de que "o leitor é invadido por um texto que o habita, e ao identificar-se com os heróis da narrativa, ele decifra sua própria existência por meio da ficção", segundo Chartier (2002, p. 108). Portanto, nessa direção, as leituras são intensa e intensiva, uma vez que a sensibilidade do leitor é comprometida e habita o cotidiano daqueles que se sentem envolvidos na leitura ficcional. Assim, as práticas envolveram emoções que suscitaram um "processo afetivo", já que o leitor aciona as capacidades reflexivas em uma espécie de "jogo textual" (JOUVE, 2010, p. II). A literatura pode ser analisada sob várias dimensões, desde as leituras escolares até a sua prática não obrigatória ou não profissional, ou seja, extrapolando os muros da escola e produzindo ressonâncias ao longo da vida.

As experiências pedagógicas envolveram o corpo, o movimento e o brincar propostas às crianças. $O$ enfoque dado também identifica o acesso à leitura literária disponibilizadas por meio de 
ações que priorizam a acessibilidade do livro à comunidade em geral e potencializadas pela criação, imaginação e invenção artística. $O$ alcance esperado, portanto, foi a abrangência da comunidade de leitores e leitoras em potencial.

\section{Ressonâncias: palavras finais}

O amarelo dos girassóis de Van Gogh é um amarelo puro, novo, denso e inquietante, que não é objeto de um reconhecimento. $O$ amarelo de Van Gogh não é recognitivo, mas problemático. Mas, uma vez experimentado, faz-nos ver o nosso mundo diferentemente (KASTRUP, 200I, p. 21).

Arte experimentada. Mudança de perspectiva. Possibilidades. (Re)Construção de saberes. (Re)Invenção de si e do mundo. Escuta sensível. Mobilização dos sentidos. Criação. A leitura literária e o contato com o livro como possibilidades de experimentação e de ampliação, intimamente interligadas com outras linguagens artísticas. Aprendizagens e (des)aprendizagens do conhecimento em processos contínuos de construção e desconstrução de saberes, destacando a arte como uma via de intercâmbios de imagens e escritos.

A experiência com a literatura e com a arte em geral caracteriza-se "por um tempo de ressonâncias", segundo Kastrup (2015, p. 246). Assim, a experiência estética para uma aprendizagem inventiva reafirma a interlocução possível entre aprendizagens, artes e invenção. Experimentar sensações, produzir sentidos em vivências que permitam processos de criação, em oficinas literárias, produzem um encontro com a leitura capaz de habitar "o campo da palavra", "habitar um território" e assim, ampliar os modos de ler.

Livros e leitores revelados em intercâmbios de leituras nas instituições escolares reafirmam que a literatura é uma manifestação universal da humanidade em todos os tempos, pois cada sociedade "cria as suas manifestações ficcionais, poéticas e dramáticas de acordo com os seus impulsos, as suas crenças, os seus sentimentos, as suas normas", de acordo com Candido (2004, p. 175). Na medida em que o escritor, atento ao mundo em que vive, transporta para o universo artístico uma forma específica e particular "de ver e dizer" esse mundo. Ele "inventa" seu mundo representacional e, ao fazê-lo, carrega experiências vividas potencializando o mundo dos seus leitores.

Dessa maneira, os livros literários são (re) construção, problematização da vida social, sob a percepção de um autor, de uma autora. Daí a força e a possibilidade de tomar a conceituação de representação do mundo por meio da literatura. Considerando que o escritor é alguém que vê e registra o mundo real com a lente do sensível, da imaginação, da criatividade e, muitas vezes, da indignação e da denúncia, por isso, a literatura coloca-se como uma possibilidade ímpar para as práticas pedagógicas nos contextos educacionais. 
Portanto, se reconhecemos que a literatura é outra forma de ver e dizer o mundo a partir do que o escritor constrói, ele se utiliza desse meio como um ato de "acender uma lâmpada", ou "um toco de vela", ou ainda através de repetidos riscos de fósforos na tentativa de evitar "a escuridão", como afirmou o próprio Erico Verissimo (198I). Então, trabalhos dessa natureza podem provocar "processos de significação" do mundo que nos cerca com as lentes da literatura e outras linguagens artísticas.

A construção deste trabalho foi formulada em etapas que se entrecruzam recorrentemente na perspectiva de promover a formação de crianças leitoras que leem com fruição e que expressam o seu mundo por meio de linguagens artísticas. Os procedimentos envolvidos fornecem dados sobre as práticas de leitura em diálogos com experimentações artísticas, e, assim, potencializam o debate e desenvolvimento de estratégias educativas que permitam repensar a formação de leitores e, consequentemente, os modos de leitura no contexto histórico-sociocultural.

\section{Referências:}

ABREU, M. Cultura letrada: literatura e leitura. São Paulo: Editora UNESP, 2006.

ANDRADE, I. Q. de; FERES. B. dos S. Atividades multissensoriais: uma proposta de mediação em leitura. In: IX SEMINÁRIO DOS ALUNOS DOS PROGRAMAS DE PÓS-GRADUAÇÃO DO INSTITUTO DE LETRAS DA UFF - ESTUDOS DE LINGUAGEM, 2018, Niterói. Anais [...] Niterói: UFF, 20I8. Disponível em: http://www.anaisdosappil.uff.br/index.php/IXSAPPIL-Ling/article/view/974. Acesso em: 10 out. 2019.

\section{ASSOCIAÇÃO NACIONAL DE PÓS-GRADUAÇÃO E PESQUISA EM EDUCAÇÃO. Ética e} pesquisa em educação: subsídios. Rio de Janeiro: ANPEd, 2019.

BARBOSA, A. M. A imagem no ensino da arte: anos 1980 e novos tempos. 8. ed. São Paulo: Perspectiva, 2010.

BARROS, M. Memórias inventadas: a terceira infância; iluminuras de Martha Barros. São Paulo: Editora Planeta do Brasil, 2008.

BARROS, M. Exercícios de ser criança: bordados de Martha Dumont. São Paulo: Salamandra, 2009.

BARROS, M. Poesia completa. São Paulo: Leya, 2010.

BRASIL. Ministério da Educação. Secretaria de Educação Básica. Diretrizes curriculares nacionais para a educação infantil. Brasília: MEC/SEB, 2010.

BRASIL. Ministério da Educação. Base nacional comum curricular. Brasília: MEC/SEB, 2018. Disponível em: <http://basenacionalcomum.mec.gov.br/images/BNCC_El_EF_I 05 I8_versaofinal_site.pdf>. Acesso em: 10 jan. 2019. 
BÉGIN, M. Le forum de discussion sur Internet comme lieu d'étude de la réception des productions littéraires jeunesse: le cas de la série Pavel I. Communication, Lettres Et Sciences du Langage, Canadá. v. 5, n. I, ago. 20I I. p.6-20.

BETHÂNIA, M. Caderno de Poesias. UFMG. 2015. Audiovisual (75 min). Disponível em: https://www.youtube.com/watch?v=if4lexb3rr4. Acesso em: 02 jul. 2020.

CANDIDO, A. Vários escritos. SP, RJ: Duas Cidades/Ouro sobre azul, 2004.

CAVALLO, G.; CHARTIER, R. (Coords.). Histoire de la lecture dans le monde occidental. Paris: Éditions Seuil, 1997.

CERTEAU, M. de. A invenção do cotidiano: I artes de fazer. I4 ed. Petrópolis, Rio de Janeiro: Vozes, 2008.

CHARTIER, A.; HÉBRAD, J. Discours sur la lecture (1880-2000). Paris: BPI - Centre Georges Pompidou, Fayard (Nouvelles études historiques), 2000.

CHARTIER, R. A história cultural: entre práticas e representações. Rio de Janeiro: Bertrand Brasil, 1990.

CHARTIER, R. O mundo como representação. Estudos Avançados, São Paulo, v. 5, n. II, jan./abr., 1991.

CHARTIER, R. Textos, impressão, leituras. In: HUNT, L. A nova história cultural. São Paulo: Martins Fontes, 1992.

CHARTIER, R. (Org.). Práticas de leitura. São Paulo: Estação Liberdade, 1996.

CHARTIER, R. A ordem dos livros: leitores, autores e bibliotecas na Europa entre os séculos XIV e XVIII. Brasília: UNB, 1994.

CHARTIER, R. Cultura escrita, literatura e história. Porto Alegre: Artmed, 200I.

CHARTIER, R. À beira da falésia: a história entre incertezas e quietudes. Porto Alegre: Editora da UFRGS, 2002a.

CHARTIER, R. Os desafios da escrita. São Paulo: Editora UNESP, $2002 b$.

CHARTIER, R. Leituras e leitores na França do antigo regime. São Paulo: Editora UNESP, 2004.

CHARTIER, R. A aventura do livro: do leitor ao navegador: conversações com Jean Lebrun. Tradução de Reginaldo Carmello Corrêa de Moraes. São Paulo: Editora UNESP, 2009a.

CICERO, A. C. Poemas escolhidos. 3 ed. Rio de Janeiro: Editora Record, 1996.

DARNTON, R. O beijo de Lamourette: mídia, cultura e revolução. São Paulo: Cia. das Letras, 1995.

DARNTON, R. A questão dos livros: presente, passado e futuro. São Paulo: Companhia das Letras, 2010. 
ECO, U. Obra aberta. São Paulo: Perspectiva, 2003.

ECO, U. Lector in fabula. São Paulo: Perspectiva, 2004.

FRAGO, A. V.; ESCOLANO, A. Currículo, espaço e subjetividade: a arquitetura como programa. Rio de Janeiro: D\&PA, 1998.

JOUVE, V. La lecture. Paris: Hachette Collection - Contours Littéraires, 2008.

JOUVE, V. Pourquoi étudier la littérature? Paris: Armand Colin, 2010.

JULIA, D. A cultura escolar como objeto histórico. Revista Brasileira de História da Educação, Campinas/SP, n. I, p. 9-43, jan./jun., 200I.

KASTRUP, V. Sobre livros e leitura: algumas questões acerca da aprendizagem em oficinas literárias. In: KASTRUP, V.; TEDESCO, S.; PASSOS, E. Políticas da cognição. Porto Alegre: Sulina, 2015.

KASTRUP, V. Aprendizagem, arte e invenção. Revista Psicologia em Estudo, Maringá, v. 6, n. I, p. 17-27, jan./jun. 2001.

LOPES, E. M. T.; GALVÃO, A. M. de O. História da educação. Rio de Janeiro: DP\&A, 200 I.

MORAIS, R. T. P. de. Modos de ler o impresso, modos de escrever na internet: escritas de leitores e leitoras do escritor Erico Verissimo. 2014. Tese (Doutorado em Educação) - Programa de Pós-Graduação em Educação, Faculdade de Educação, Universidade Federal de Pelotas, Pelotas, 2014.

PAULINO, M. das G. R. Algumas especificidades da leitura literária. In: PAIVA, A. et al. (orgs.).

Leituras literárias: discursos transitivos. Belo Horizonte: Ceale/Autêntica, 2008.

PESAVENTO, S. J. História e história cultural. Belo Horizonte: Autêntica, 2005.

PIORSKI, G. Brinquedos do chão: Reflexões sobre o brincar na infância. Brasil: Editora Peirópolis, 2016.

RIBEIRO, V. M. (org.). Letramento no Brasil. São Paulo: Global, 2003.

SILVA, E. T. Leitura na escola e na biblioteca. 3. ed. Campinas (SP): Papirus, I99I.

SOARES, M. Ler, verbo transitivo. In: PAIVA, A. et al. (orgs.). Leituras literárias: discursos transitivos. Belo Horizonte: Ceale/Autêntica. 2008.

SOUZA, R. J. de (org.). Biblioteca escolar e práticas educativas: o mediador em formação. Campinas: Mercado de Letras, 2009.

SUZUKI, C. L. Cadernos de artista: páginas que revelam olhares da arte e da educação. 20I4. Dissertação (Mestrado em Educação) - Escola de Comunicação e Artes, Universidade de São Paulo, São Paulo, 2014.

UNIVERSIDADE FEDERAL DE MINAS GERAIS - UFMG. Caderno de poesias, Maria Bethânia. 2015. Disponível em: https://www.youtube.com/watch?v=uSiENII_O34. Acesso em: 2 jul. 2020.

VERISSIMO, E. Solo de clarineta I. Vol. I. I5. ed. Porto Alegre: Editora Globo, I98I. 
Recebido em: 25 de março de 2021 .

Versão corrigida recebida em: 30 de julho de 202I.

Aceito em: 03 de agosto de 2021 .

Publicado online em: 03 de setembro de 2021.

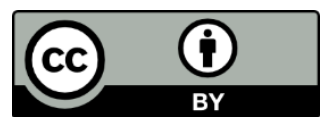

